\title{
ENERGY TRANSPORT CONTROL IN WINDOW SYSTEMS
}

\author{
A.l. Berlad, F.J. Salzano, and J. Batey
}

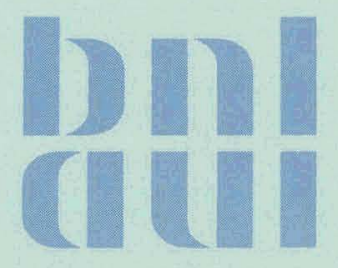

September 15, 1976

\section{DEPARTMENT OF APPLIED SCIENCE}

BROOKHAVEN NATIONAL LABORATORY ASSOCIATED UNIVERSITIES, INC. UNDER CONTRACT NO. EY-76-C-02-0016 WITH THE UNITED STATES ENERGY RESEARCH AND DEVELOPMENT ADMINISTRATION 


\section{DISCLAIMER}

This report was prepared as an account of work sponsored by an agency of the United States Government. Neither the United States Government nor any agency Thereof, nor any of their employees, makes any warranty, express or implied, or assumes any legal liability or responsibility for the accuracy, completeness, or usefulness of any information, apparatus, product, or process disclosed, or represents that its use would not infringe privately owned rights. Reference herein to any specific commercial product, process, or service by trade name, trademark, manufacturer, or otherwise does not necessarily constitute or imply its endorsement, recommendation, or favoring by the United States Government or any agency thereof. The views and opinions of authors expressed herein do not necessarily state or reflect those of the United States Government or any agency thereof. 


\section{DISCLAIMER}

Portions of this document may be illegible in electronic image products. Images are produced from the best available original document. 


\title{
ENERGY TRANSPORT CONTROL IN WINDOW SYSTEMS
}

\author{
A.l. Berlad, ${ }^{*}$ F.J. Salzano, and J. Batey
}

September 15, 1976

*State University of New York, Stony Brook, N.Y. 11794

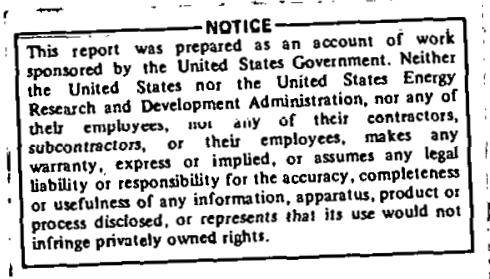

\section{DEPARTMENT OF APPLIED SCIENCE}

BROOKHAVEN NATIONAL LABORATORY

UPTON, NEW YORK' 11973 


\section{NOT I C E}

This report was prepared as an account of wurk sponsorcd by the United States Government. Neither the United States nor the United States Energy Research and Development Administration, nor any of their employees, nor any of their contractors,

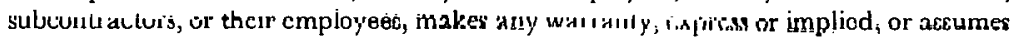
any legal liability or responsibility for the accuracy, completeness or usefulness of any information, apparatus, product or process disclosed, or represents that its use would not infringe privately owned rights.

Printed in the United States of America Available from

National Technical Information Service U.S. Department of Commerce

5285 Port Royal Road

Springfield, VA 22161

Price: Printed Copy $\$ 4.00$; Microfiche $\$ 3.00$

Novembcr 1976

855 ropies 
THIS PAGE

\section{WAS INTENTIONALLY LEFT BLANK}




\section{ABSTRACT}

Energy transport in window systems involves conductive, convective and radiative processes. Currently utilized twinpane systems generally inhibit convective transport through the use of small pane separation distances. These distances are normally of the order of 0.5 inch. However, substantial increases in pane separation distances do not necessarily imply supercritical Rayleigh numbers, and correspondingly high convectively-influenced heat loss rates. Large pane separations and subcritical Rayleigh numbers may both be achieved if other convection defeating devices are employed in the interpane regime. This study is concerned with possible new convection defeating apparatuses and techniques for window systems. It is found that selected convection defeating. equipment may also be used for effective radiation and conductive control. Heat transfer measurements of initial window designs confirm the utility and promise of the window systems under study. 


\section{Introduction and Background}

The most common forms of window systems are either single or double-glazed. It is well established'that conductiveconvective-radiative heat losses (during the heating season) through single-glass panes are enormous ${ }^{1,2}$ compared to those for an acceptably insulated wall system. For a double-glazed window system, heat loss rates can be cut approximately in half ${ }^{1,2}$ compared to a single-glaze system. This window system heat loss rate can be further reduced by the use of a variety of low emissivity coatings. 2 Even with such (costly) approaches, twin-glazed window systems remain substantially inferior to insulated wall systems.: A well insulated wall system may be expected $^{1}$ to have a $U$ value of less than $0.10 . \mathrm{Btu} / \mathrm{ft}^{2} \mathrm{hr} \mathrm{O}_{\mathrm{F}}$. (Recent examples of energy effective residential ${ }^{3}$ and commercial 4 structures have wall values of $U \leq 0.06 \mathrm{Btu} / \mathrm{ft}^{2} \mathrm{hr} \mathrm{O}_{\mathrm{F}}$ ) ) It has been noted ${ }^{2}$ that these seemingly poor window $U$ values do not reflect fairly the heating season performance of a suitably oriented, double-glazed window system. A south-facing doubleglazed window system may provide a net positive heat transfer to a residential structure, integrated over the heating season. of course, such a window system (solar collector) may present a number of problems:

(a) Bpatial nunlsothermality of a structure's conditioned space, unless adequate (air) circulation is provided, to distribute the insolation energy.

(b) Temporal nonisothermality of a structure whose thermal storage characteristics are inadequate (typical case).

(c) Poor temperature control of the conditioned space.

(d) Unwanted insolation during nonheating season periods, thereby increasing space cooling costs. 
Designers of residential or commercial energy conservative structures $^{3,4}$ have generally decided that low energy costs and problem-avoiding designs are best achieved by reducing the relative wall area devoted to window systems. That is, doubleglazed window systems (with or without selected coatings) are employed sparingly.

Previous analyses 5,6 have indicated how comfort Range Thermal storage $\left(\mathrm{e} . \mathrm{g}\right.$. , in the range $65^{\circ} \mathrm{F}-75^{\circ} \mathrm{F}$ ) may be employed to suppress the temperature-leveling problems associated with the residential or commercial use of archltecluial window systems. Given adequate thermal storage, ${ }^{6}$ the technical requirements imposed on a superior window system include:

(a) High transmissivity to insolation, during the heating season.

(b) High solar reflectivity/shading during the nonheating season.

(c) Low U value during all seasons.

(d) Low infrared radiative exchanye between tho two winnow panes.

(e) Initial and operating cusls which malkc energy conservation economically attractive.

In the following portions of this report, we re-examine some nf. the important energy transport mechanisms which shape the behavior of double-glazed window systems. We then examine the utility of proposed new window system designs.

\section{Heat Transfer Through Window Systems}

Normal insulating materials are generally characterized in terms of a thermal resistance, $R$. (ft ${ }^{2}$ hr ${ }_{F}$. Btu) Thermal resistors in series are simply related by ${ }^{1}$ 


$$
\mathrm{R}_{\mathrm{T}} \cdot=\mathrm{R}_{1}+\mathrm{R}_{2}+\mathrm{R}_{3}+\cdots-\mathrm{R}_{\mathrm{n}}
$$

where the frequently tabulated $U$ value (Btu/ft ${ }^{2} \mathrm{hr} \mathrm{O}_{F}$ ) is given $\mathrm{by}^{1}$

$$
\left(\frac{1}{U}\right)=R_{T}=\frac{1}{f_{i}}+\frac{x}{k}+\frac{1}{f_{O}}
$$

$f_{i}$ and $f_{0}$ are the inside (surface) and outside surface "conductance coeeficients." Values $f_{i}$ and $f_{o}$ depend upon the materials used as well as local fluid dynamic properties that may influence heat transfer through a composite (insulating) material. For a simple, steady state heat transfer process between two large spatial regimes; separated by a planar layer of a given U value, the rate of heat transfer is given by

$$
\dot{q}^{\prime \prime}=U(\Delta \mathrm{T})=\left[\frac{\mathrm{Btu}}{f t^{2} h r}\right] \text {. }
$$

Here, $\Delta \mathrm{T}$ is the difference between the two temperatures which are used to characterize the two large spatial regimes.

Expressions (1) - (3) are common to characterization of a broad range of composite materials. The reason for this commonality is quite fundamental. It derives from the fact that molecular thermal conduction is the principal transfer mechanism controlling the transport of heat through the material of interest.

Equations (1) - (3) are not universdly applicable to windows. Window systems simultaneously sustain conductive, convective, and radiative transport processes. ${ }^{1,2}$ As a result, a simple increase in the thickness of a window system (e.g., increase in the air gap size of a double-glazed window) does not necessarily lead to a corresponding increase in the effective thermal resistance of the window. calculated results given in Reference 2 illustrate 
this fact. Thus, as the air gap size for a double-glazed window is increased beyond some optimum, free convection becomes an increasingly more important transport mechanism, thereby increasing the effective heat transfer coefficient for the window. ${ }^{7}$. Berman and silverstein ${ }^{2}$ have reviewed some of the salient heat transfer features of common window systems and discussed some approaches to suppressing heat transfer mechanisms. These approaches generally involve:

(a) The selection of an "Optimuu" air gap spacing in double-pane winkows.

(b) The use of low (infrared) emissivity coatings affixed to the interior (air gap) surfaces of the two panes--thereby reducing the radiative heat exchange across the air gap.

(c) The use of a high molecular weight gas in the "air" gap, thereby reducing the molecular transport coefficients.

The above three considerations are all effective ${ }^{2}$ in reducing heat transfer through a window system. As a group, however, they in not. satisfy all of the five criteria previously noted (Part I) for a superior window system--one which could be used effectively for a low loss, architectural window (and solar collertor window) :

(a) High transmissivity to solar radiation during the heating season.

(u) High anlar reflestivity/shading during the nonheating season.

(c) Low U values during all seasons.

(d) Low infrared radiative exchange between the two window panes.

(e) Cost effective design. 
In order to identify some characteristics of a window system that can suppress free convection, even as an air gap thickness is increased, we examine some heat transfer data for nonmetallic and for aluminum honeycomb arrays (Figures 1 and 2).

Figure 1 gives the thermal resistance for commercially available, thin-wall nonmetallic (plastic) honeycomb arrays, as a function of cell size and core thickness. If honeycomb behaved as an "ordinary insulating material," the relation between its Resistance, $R$, and its core thickness, $\delta_{x}$ ' would be given by

$$
R=R_{1} \delta_{x}
$$

where $R_{1}$ is the thermal resistance of a unit thickness (for a given cell size). Examination of the (experimentally determined) Figure 1 data shows that equation (4) does not hold, exactly. However, the individual (R) vs. ( $\delta$ ) curves are almost linear and the nonmetallic honeycomb of Figure $I$ has the necessary feature-the thermal resistance is a monotonic increasing function of core thickness. This is a necessary characteristic of a cellular array wherein free convective flow patterns are relatively independent of core thickness. ' In turn, this is a necessary characteristic of a window system which contains a cellular array, whose purposes are to inhibit free convection phenomena while permitting solar transmittance.

$\dot{A}$ substantial literature is available describing the heat transfer characteristics of a number of celiular arrays."13 It is generally found that there exists a critical Rayleigh number, above which heat transfer rates cannot be explained purely in terms of molecular transport processes. The Rayleigh number is given by 


$$
\mathrm{R}_{\mathrm{a}}=\frac{\mathrm{g \beta}\left(\mathrm{T}_{1}-\mathrm{T}_{2}\right) \mathrm{d}^{3}}{\alpha \nu}
$$

where $F=$ coefficient of volume expansion, $g$ = acceleration due to gravity; $T_{1}$ and $T_{2}$ are the characteristic temperatures of the system; $d$ = characteristic dimension of a one-dimensional system (or effective characteristic dimension of a multidimensional system); $a$ = thermal diffusivity; $\nu=$ kinematic viscosity.

For Rayleigh numbers below $\approx 10^{3}$, the mode of heat transfer is generally found to be independent of significant free convective effects.

Suppression of free convective effects through cellularization of air spaces (and reduction of characteristic Rayleigh numbers) is clearly not sufficient for the successful design of a low heat loss window system. Figure 2 shows the large heat transfer rates that can derive when high thermal conductivity honeycomb materials (e.g., aluminum) are employed. It is further clear that optical losses (for either reflective or transparent nonnetallic honeycomb materials used in solar collector'windows) can be significant. ${ }^{10}$ This is particularly true for cases where insolation angles are surstantially off-axis with respect to a thick honeycomb core. Additional problems may be presented by nonmetallic honeycomb (convection defeators) which relate to radiation control (day vs. night and summer vs. winter) as well as to consumer acceptability.

\section{Low Heat Loss Fenestration - A Design Approach}

Figure 3 gives the schematicn of a Julwecn the-glass convection-radiation control system which appears to satisfy the previously noted features required of low heat transfer 
window systems. Design features include a multiple venetian blind window system for which

(a) The venetian blind array can be withdrawn (remotely) to provide maximum optical fidelity.

(b) The angle of inclination of the primary (large) blinds can be varied to permit optimum transmission. (winter) or reflection (summer) of sunshine.

(c) Highly reflective secondary blinds can be actuated in order to provide privacy, additional air gap cellularization, and virtual radiative decoupling of the two interior infrared active pane surfaces which define the air gap dimension.

(d) Small variations in the angle of inclination of the primary blind are not expected to result in unacceptably large characteristic Rayleigh numbers.

There are currently available commercial window systems which employ between-the-glass venetian blinds to provide heat and light control. Current systems generally suffer from the following deficiencies:

(a) Air gap (core) dimensions are such that

(1) large decreases in $U$ values are not achieved, and/or

(2) setting the venetian blind in the "closed" position permits very large characteristic Rayleigh numbers (and free convective losses) to be obtained.

(b) Radiative decoupling of the two interior infrared active pane surfaces can be achieved only partly (closed position). This is under conditions where free convective losses are greatest. 
(c) "Privacy". is achieved by "closing" the blind, thereby increasing free convective effects.

other studies ${ }^{2}$ have noted the importance of suppression of unwanted (infrared) radiative exchange between the interior surfaces of the two window panes. To illustrate the suppression of this exchange by the Figure 3 design, we consider the emissive properties of the two panes (Figure 4). $\varepsilon_{b}$ and $\varepsilon_{c}$ are the surface emissivities to be considered here. The radiative heat transfer rate is given by

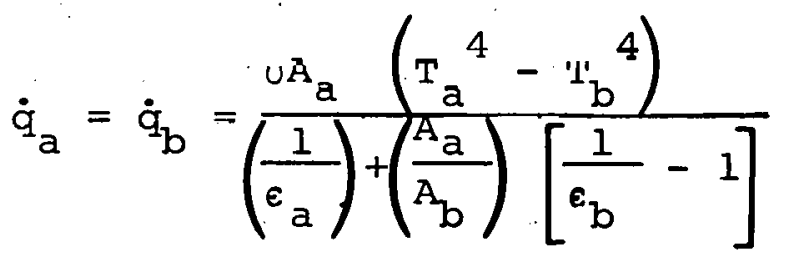

where

$$
\begin{aligned}
& \dot{\mathrm{q}}=\text { total heat transfer rate, }[\mathrm{Btu} / \mathrm{hr}] \\
& \dot{\mathrm{q}}^{\prime \prime}=\text { heat transfer rate per unit area, }\left[\mathrm{Btu} / \mathrm{ft}^{2} \mathrm{hr}\right] \\
& \mathrm{A}_{\mathrm{a}} \cdot \mathrm{A}_{\mathrm{b}}=\text { area of surfaces } a, b \text {, respectively } \\
& \varepsilon_{\mathrm{a}} \cdot \epsilon_{\mathrm{b}}=\text { emissivities of surfices } a, b, \text { rccpcctively } \\
& T=O_{R}
\end{aligned}
$$

For the case of plane parallel surfaces, one shtains

$$
\dot{q}_{\mathrm{a}}^{\prime \prime}=-\dot{\mathrm{q}}_{\mathrm{b}}^{\prime \prime}=\frac{\sigma\left(\mathrm{T}_{\mathrm{a}}^{4}-\mathrm{T}_{\mathrm{b}}^{4}\right)}{\left(\frac{\epsilon_{\mathrm{a}}+\varepsilon_{\mathrm{b}}}{\epsilon_{\mathrm{a}}{ }^{6} \mathrm{~b}}\right)-1}
$$

where, employing the nomenclature of Reference 2

$$
\dot{\mathrm{q}}_{\mathrm{a}}^{\prime \prime}=\mathrm{c}_{\mathrm{ab}} \sigma\left(\mathrm{T}_{\mathrm{a}}^{4}-\mathrm{T}_{\mathrm{b}}^{4}\right)
$$


We note that when the secondary blinds (Figure 3) are in the "closed" position, that

(a) additional cellularization of the air space obtains (reduced Rayleigh number) and

(b) highly reflective plane parallel plates (the secondary blinds themselves) make possible $c_{a b}$ values which are lower than. 0.05 (the lowest value considered in the parametric study of Reference 2).

Thus, for example, metallic finishes are possible having emissivities of less than 0.05. For such a case, $C_{a b}=0.0256 \ldots$. It is significant that for large core thicknesses (the case of interest here); low values of $c_{a b}$ are most advantageous. ${ }^{2}$ In the study of Reference 2, low $c_{a b}$ values are achieved through application of special reflective coatings on the interior window surfaces. For the fenestration system shown in Figure 3 , even lower $\mathrm{C}_{\mathrm{ab}}$ values are achieved without recourse to optical coatings on glass. In addition to cost savings, the Figure 3 arrangement permits greater window transmissivity (for sunshine) than is possible with coated windows.

There exist a wide range of design variations of multiple venetian blind window systems that meet the general requirements for low heat loss fenestration. Figure 5 shows a system of two primary blinds. For surface emissivities of $\leq 0.05$, such a window system can deposit solar radiation on selected interior surface areas of a structure to be solar heated. Small variations of the angles of inclination of each of the two primary blinas can be used to direct sunshine, other light, and to achieve privacy. (at no significant increase in the characteristic Rayleigh number). 
Further, the addition of secondary blinds (as in Figure 3) permits ready suppression of radiative transport mechanisms.

It is interesting to examine the effect of core thickness, $t$ (Figure 3), on fenestration heat losses. As indicated earlier, once free convective effects are suppressed, increases in core thickness leads to decreases in U values, limited only by radiative exchange and molecular transport mechanisms. With radiative losses effectively suppressed (by low $C_{a b}$ values), it is clear that the proposed design approaches imply very low U values for windows having large core thicknesses. Some initial measurements of a. simple test window arrangement has yielded U values which are less than half those generally encountered for commercially available (uncoated) twin-pane systems (see Appendix).

IV. Some Summary Remarks

Low heat loss fenestration systems can be designed which promise to have $U$ values less than a third of those typical of ordinary commercial twin-pane windows. values of

$$
U<0.2 \frac{B t u}{f t^{2} h O_{F}}
$$

appear easily achievable for thick core, twin-pane windows, suitably fitted with highly reflective, multiple venetian blind arrays which serve to inhibit the onset of free convection losses, and to suppress radiative losses. Such fenestration systems have other advantages which pertain to day vi. night and summer vs. winter operating requirements. These systems also interface advariliyeuusiy with structures that are to be solar heated (and illuminated) via architectural windows. They interface very well with structures having substantial thermal storage 
capabilities. Although window transmissivity is somewhat degraded by these multiple venetian blind arrays, it is expected that transmissivities greater than $60 \%$ (integrated over seasonal solar angles of incidence) are available. This compares well with a (0.68) transmissivity ${ }^{2}$ for ordinary twin-pane glass windows.

Accordingly, the proposed fenestration systems provide a design approach which permits the architectural use of large glass window areas (giving a heating season net energy transfer) to provide solar heating, illumination, as well as low heat loss rates when not in use as a solar collector window.

Preliminary studies indicate that such a solar collector system possesses substantial advantages over other currently proposed systems. These advantages embrace the criteria of cost, esthetics, and functional reliability. 
V. References

1. ASHRAE. Handbook of Fundamentals. 1972.

2. Berman, S. M. and Silverstein, S. D., Editors. Efficient Use of Energy-III, Energy Conservation and Window Systems. AIP Conference Proceedings No. 25. 1975.

3. Byrne, Stewart. The Arkansas Story--Energy Conservation Ideas to Build On. Report No. 1, Owens-Corning Fiberglas corp. August 1975.

4. Powell, F. J. Manchester Experiment and Building Codes. Paper presented at the March 20-21; 1974 Seminar on Energy conservation - BY Decign, Florida Engineering suciely and Florida Association of the American Institute of Architects.

5. Bcrlad, $\Lambda$. I., Salzano, F. J., and Batey, J. Enthalpy Management in Buildings: An Analysis and an Integrated Approach. Brookhaven National Laboratory Report BNL 20572, July 1975. (In Press: Energy-The International Journal)

6. Berlad, A. I., Iin, H. C., Salzano, F. J., and Batey J. Comfort Range Thermal storage. Brookhaven National Laboratory Report BNL 21591, July 1976.

7. Eckert, E. R. G., and Drake, Robert M. Jr. Heat and Mass Transfer. Published by McGraw Hill Book Company, Inc.. New York, 1959. (Second Edition)

8. Cravalho, E. G., Tien, C. L., and Caren, R. F. Effect of Small Spacings on Radiative Transfer Between Two Dielectrics. J. Heat Transfer 89, 351, November 1967.

9. Newe11, M. E., and Schmidt, F. W. Heat Transfer by Laminar Natural Convection within Rectangular Enclosures. J. Heat Transfer , 159, February 1970.

10. Hollands, K. G. T. Natural Convection in Horizontal ThinWallcd Honcycomb fanels. J. Heal Trásfer, 439, November 1973.

11. Schmidt, E. Versuche Zum Warmeubergang bei Naturlicher Konvektion. Chemie-Ing.-Techn. 28, 175, 1956. 
12. Batchelor, G. K. Heat Transfer by Free Convection Across a Closed Cavity Between Vertical Boundaries at Different Temperatures. Quart. Applied Math. 12, 209, October 1954.

13. Catton, I.., and Edwards, D. K. Effect of Side Walls on Natural Convection Between Horizontal Plates Heated from Below. J. Heat Transfer , 295, November 1967.

14. Carslaw, H. S.., and Jaeger, J. C. Conduction of Heat in Solids. Published by Oxford at the Clarendon Press, 1959. Second Edition. 


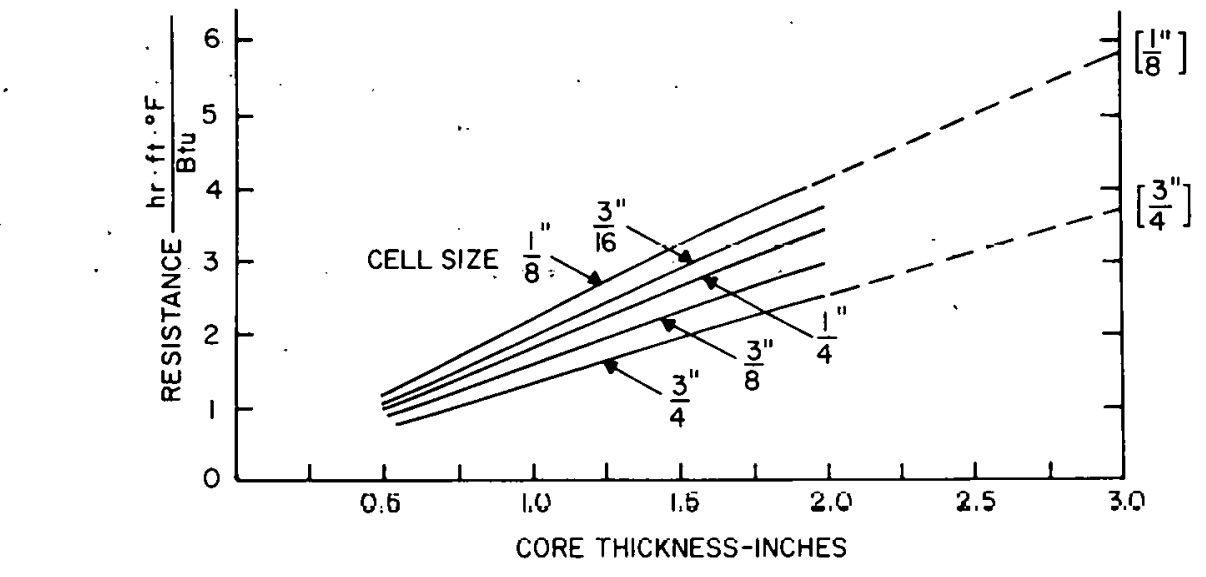

Figure 1. Non-metallic honeycomb, thermal resistance.

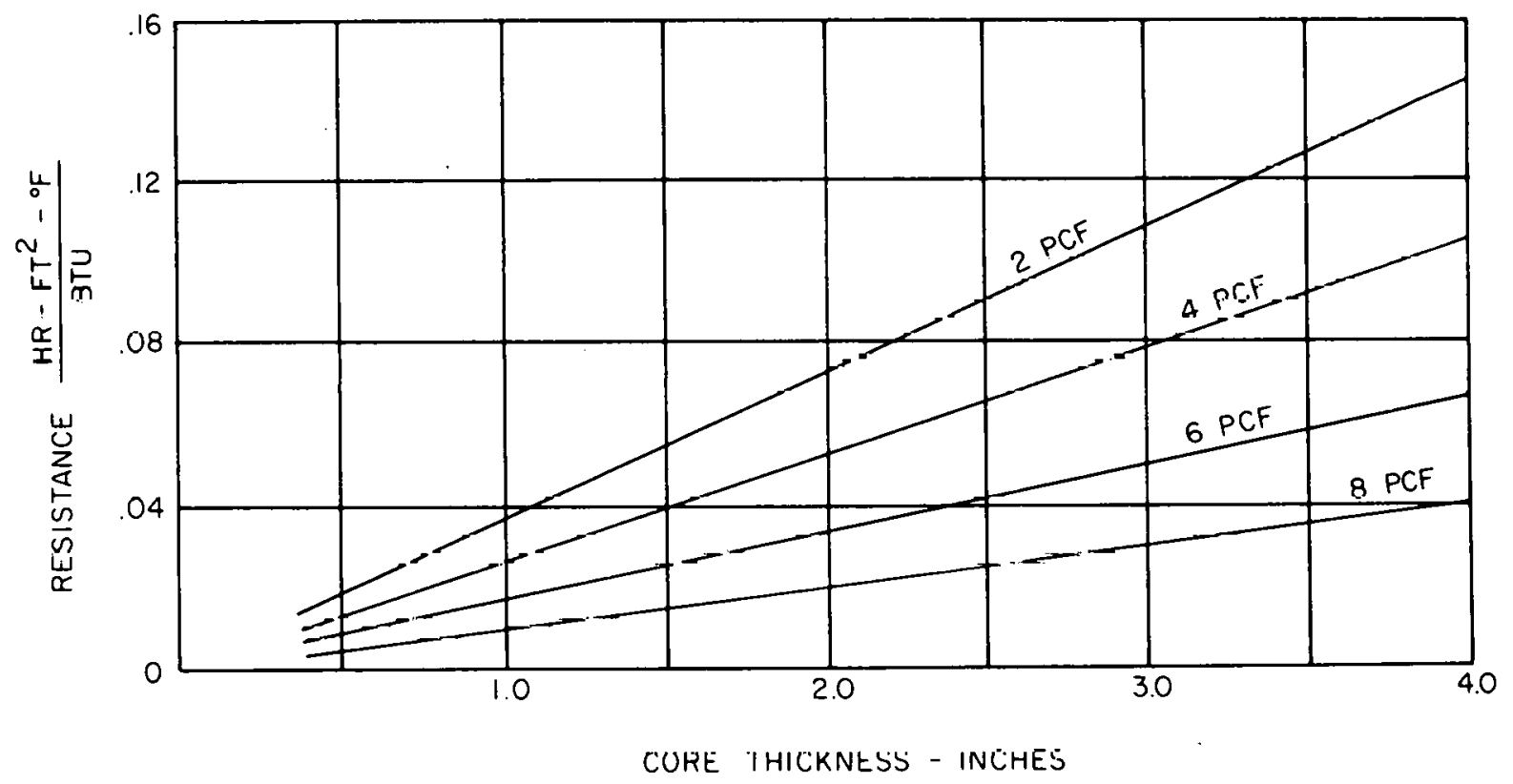

Figure 2. Aluminum honeycomb, thermal resistance. 


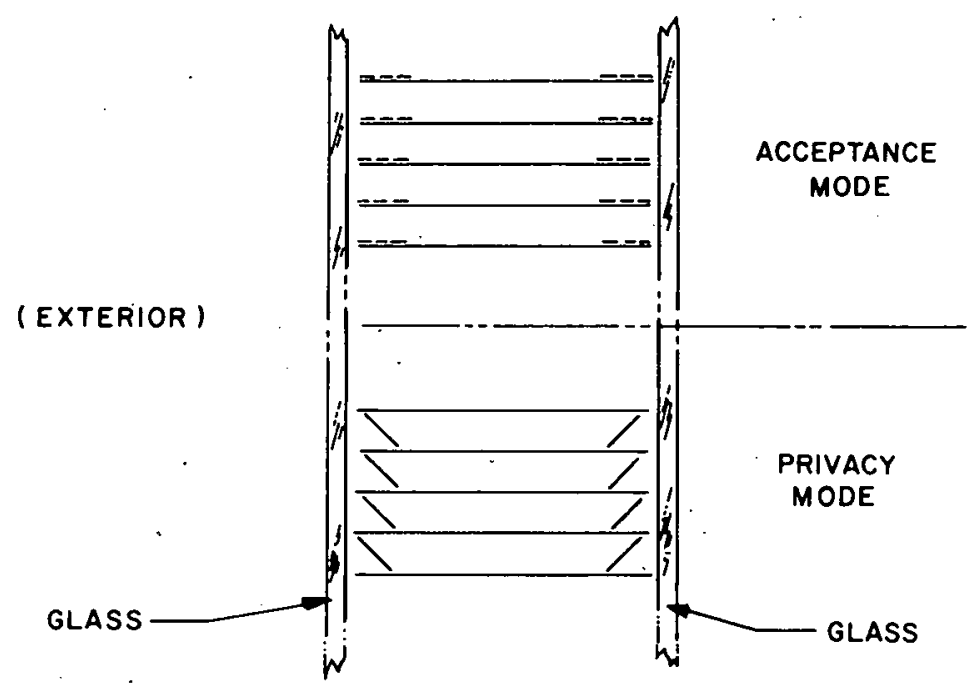

INTERIOR

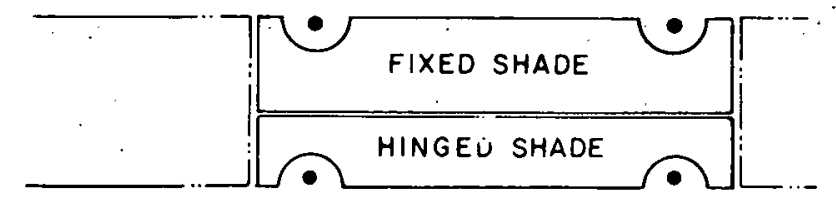

EXTERIOR

HINGED SHADE IS LIFTED BY STRINGS,

WHICH CLEAR NOTCHED EDGES OF THE

FIXED SHADE ELEMENTS

Figure 3. Radiation control and convection inhibiting fenestration. 


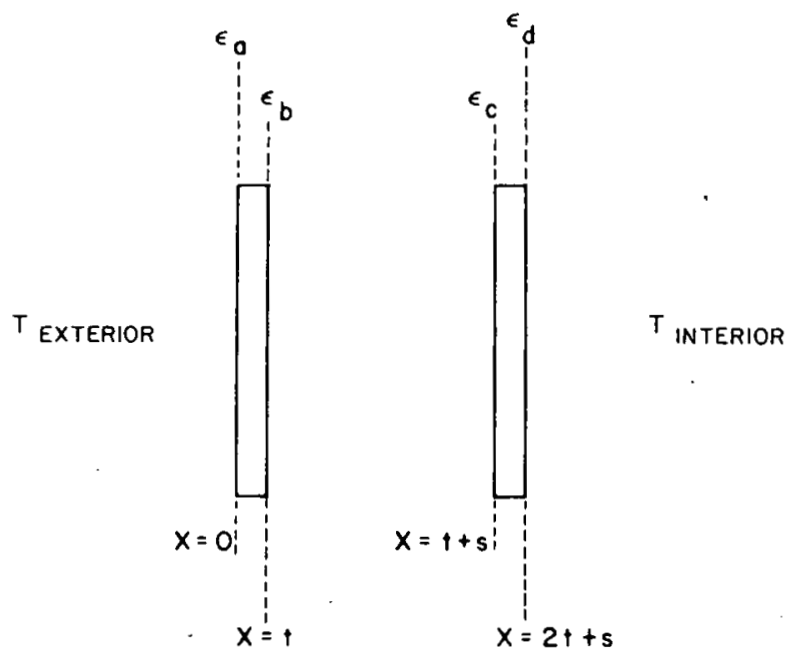

Figure 4. Double-glazed window schematic, no convection-radiation controls in air gap.

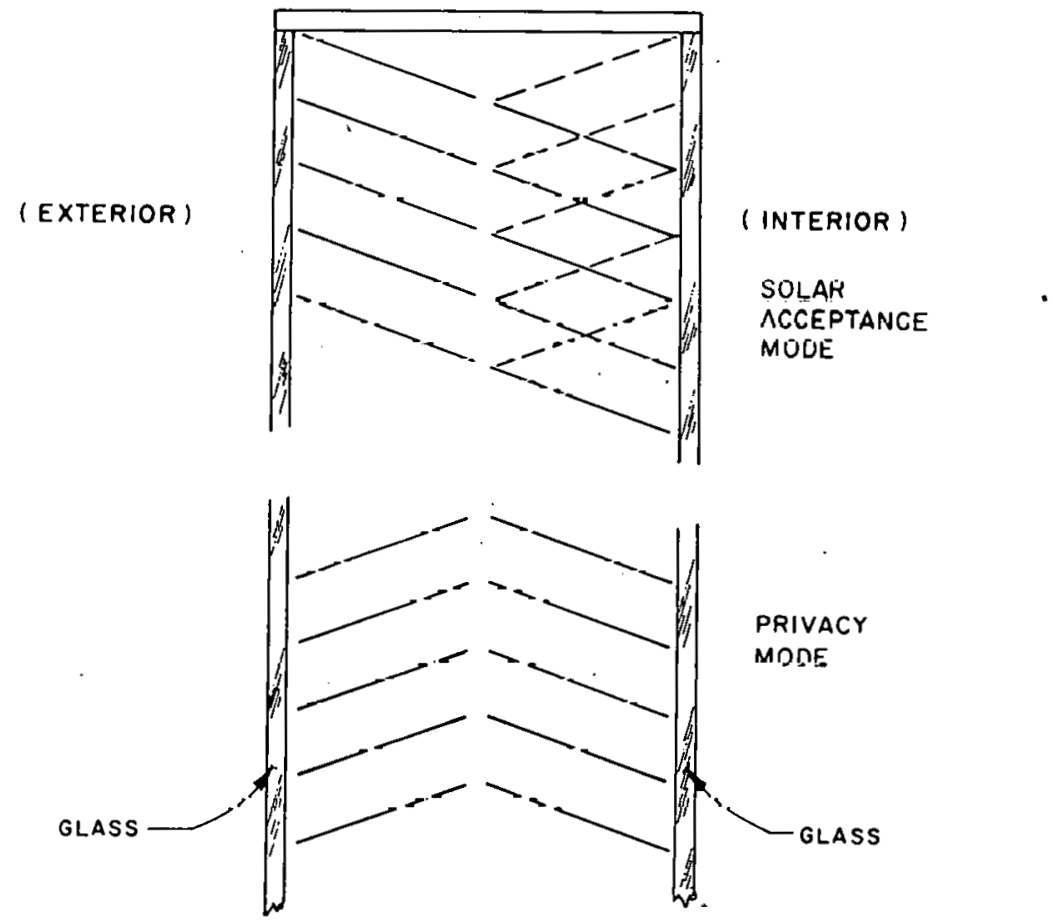

Figure 5 . Convection inhibiting fenestration. 


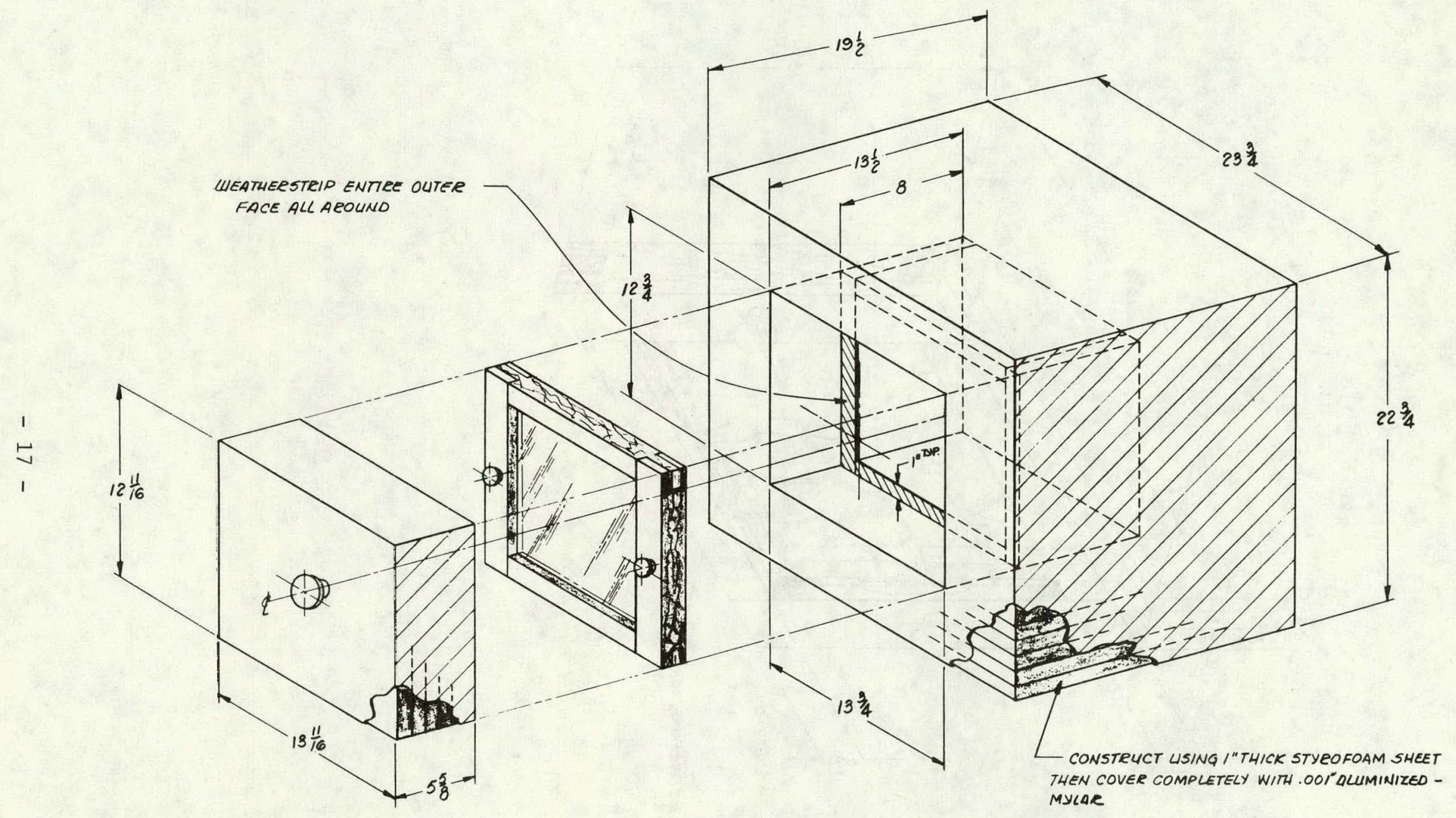

Figure 6a. Insulated test box. 


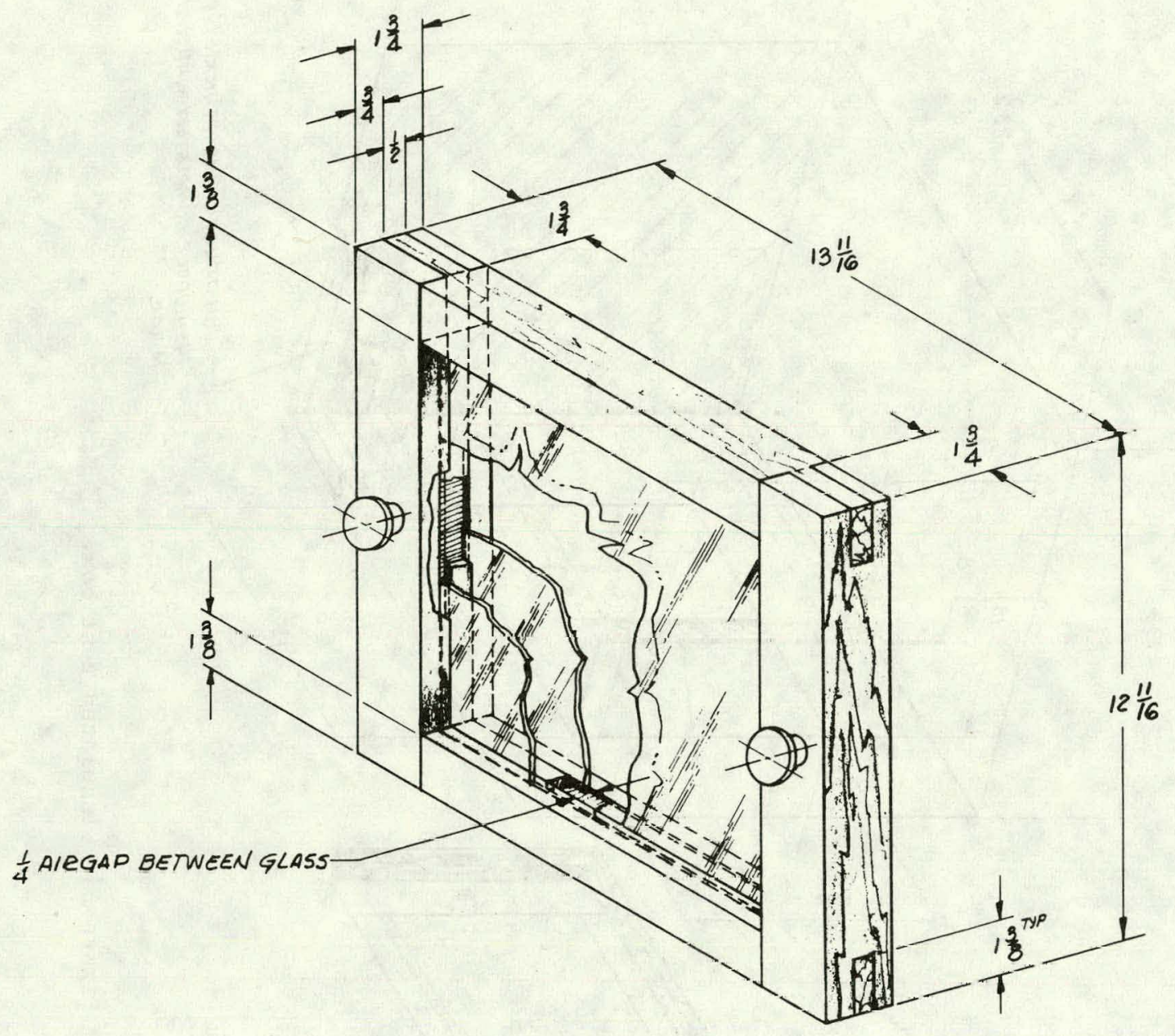

Figure $6 \mathrm{~b}$. Window. 


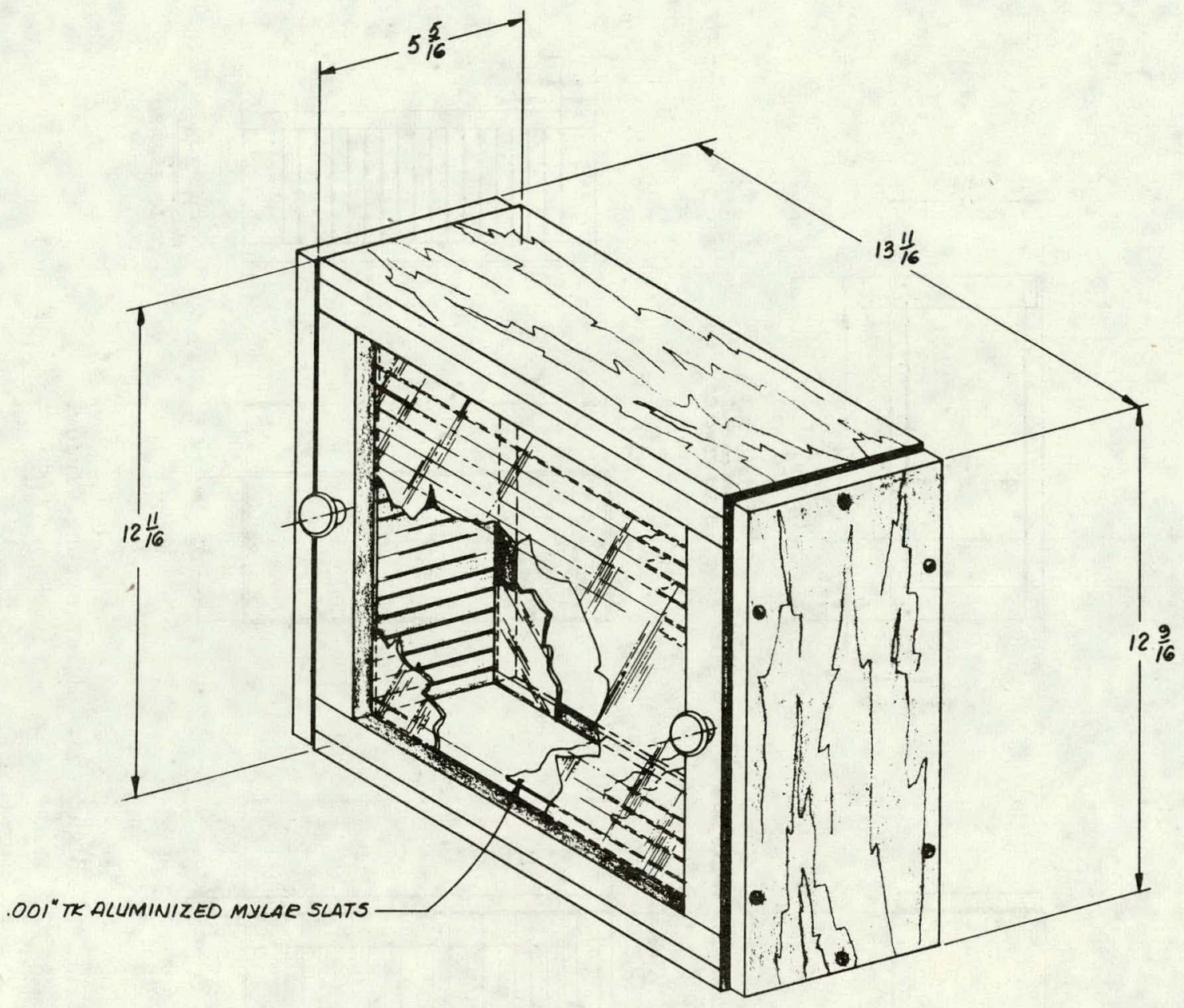

Figure 6c. Mylar strung window. 

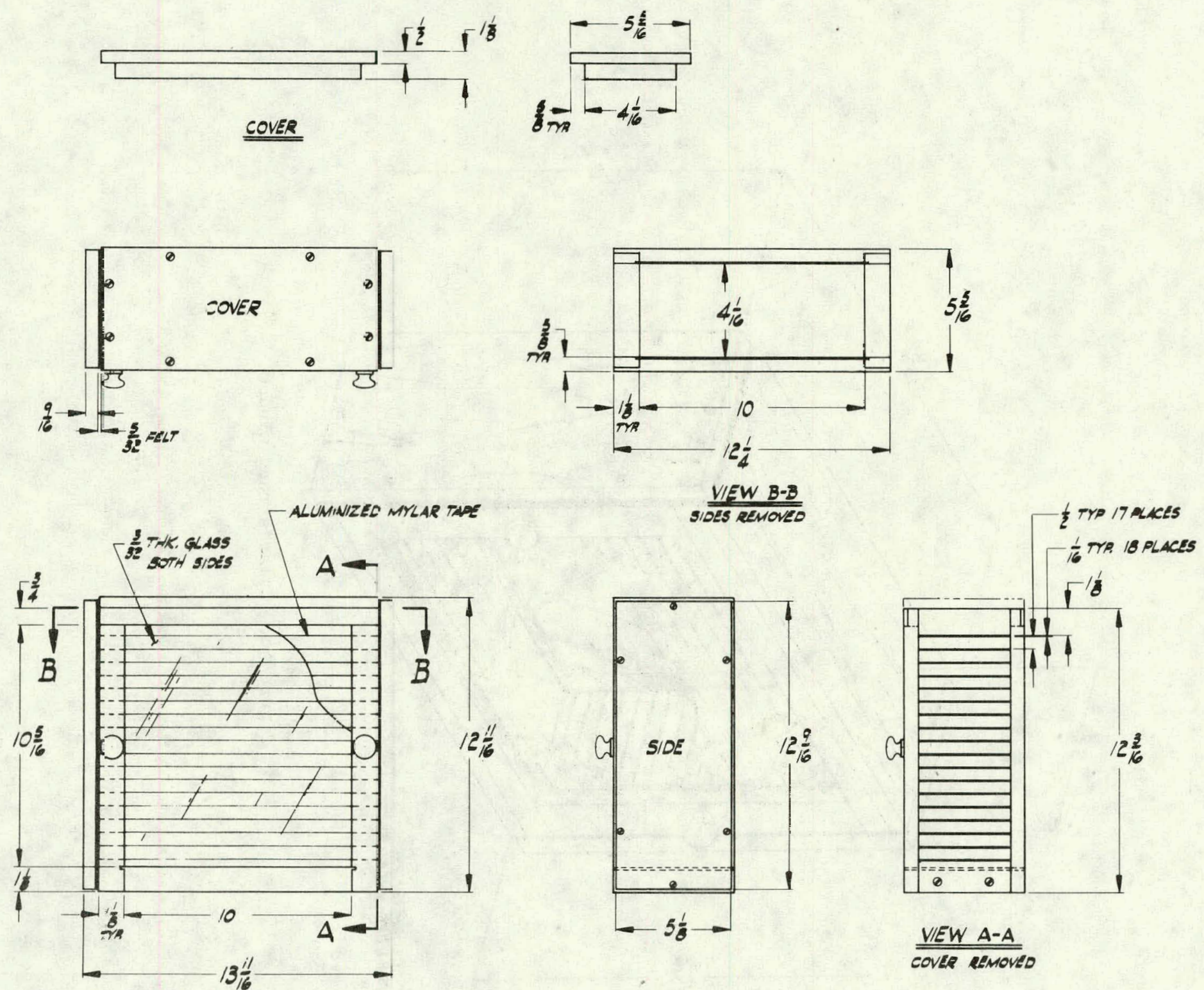

Figure 6d. Mylar strung window. 
VII. Appendix

Determination of overall U-Values for composite window Materials

To make initial evaluations of composite window elements (such as those discussed under convection-defeating and radiationcontrolling strategies) a set of simple heat transfer experiments have been conducted. These tests involve a styrofoam box which can be internally heated or cooled. One of the six sides of the box is designed to accept a (reduced size of the) composite window element of interest. The test device is shown schematically in Figures 6.

The heat transfer process through the window element is expected to be largely one-dimensional, although the heat transfer through the styrofoam box is three-dimensional. In order to analyze, via simple methods, the heat transfer rates through the composite window elements, it is useful to identify a "characteristic demonsion" for the box. This is done in terms of a geometric average of the "characteristic dimension" for the inside of the box and the "characteristic dimension" for the outside of the box. The bases for the definition and use of such a characteristic dimension derive from existing analytic solutions for multidimensional heat transfer problems. 14

We illustrate, for the spherical case: If the test apparatus were a hollow spherical shell (cooled or heated at a steady rate by its interior) then the cooling/heating rate would be given by ${ }^{14}$

$$
Q_{0}=\mp \frac{4 \pi k(\Delta T)\left(r_{a} r_{b}\right)}{\left(r_{b}-r_{a}\right)}
$$


where $r_{a}=$ inner radius, $r_{b}=$ outer radius, $\left(r_{b}-r_{a}\right)=$ shell thickness, $k=$ thermal conductivity, $(\Delta T)=$ temperature difference between outside and inside surfaces. Thus, the heat transfer rate per unit area, at any value of $r$, is given by:

$$
\dot{q}^{\prime \prime}=\frac{Q_{o}}{4 \pi r^{2}}=k(\Delta T)\left[\frac{r_{a} r_{b}}{r^{2}\left(r_{b}-r_{a}\right)}\right] .
$$

If we define $r^{*}=$ characteristic radius, to be the geometric mean of the two radii:

$$
r^{*} \equiv \sqrt{r_{a} r_{b}}
$$

then, for $x=r^{*}$, we have:

$$
\left[\dot{q}^{\prime \prime}\right]_{r^{*}}=k\left[\frac{\Delta T}{r_{b}-r_{a}}\right]
$$

and; at $r=r^{*}$, the heat transfer rate per unit area is of the identical algebraic form as that appropriate to one-dimensional, plane parallel plate heat transfer phenomena.

Accordingly, the utilization of the nonone-dimensional styrofoam box to analysis of heat transfer rates through test. window elements involves the following:

1) The interior of the box contains a constant heat source or heat sink.

2) The test section of the box is fitted tightly with a "styrofoam plug" of construction and material similar to that of the rest of the box.

3) Subject to constant exterior temperature conditions, heat loss by (or heat gain by) the box interior is measured over a substantial time period. 
4). An average heat loss rate per unit area" (based on the characteristic dimension of the box) is deduced for the box. A characteristic $U$ value for the box is then given directly.

5) The experiment is repeated, with the composite window element substituted for the "styrofoam plug." Subject to the same internal and external steady state temperature conditions, a new heat transfer rate is determined, for the same substantial time period previously employed.

6) The characteristic area of the styrofoam box (based on its characteristic dimension) and its previously determined U-value is employed to determine the "box heat loss" for the time period of interest. The remainder of the observed heat loss can be ascribed to the test element. The $U$ value (and axea) of the (wood) frame holding the composite glass element is known. Accordingly, we may then use standard methods to deduce the $U$ value for the composite window material.

An $a b$ initio set of experiments have been conducted to determine the effective $U$ values for the test apparatus (styrofoam box with plug) and for a double-glazed $(4.0625$ inch air gap) window element (Fig. 6 ). In the latter case, the air gap volume is further divided into a large number of 0.5 inch high regimes, each defined by two glass sides, two wood frame sides, and two 4.0 inch deep sides of 0.001 inch aluminized mylar (Figures 6). 
For the no-wind condition, an ambient interior (box) temperature of $0^{\circ} \mathrm{C}$ and an ambient exterior (box) temperature of $20^{\circ} \mathrm{C}$, the following U-values have been determined:

Styrofoam Box: $\quad U \simeq 0.02 \mathrm{Btu} / \mathrm{ft}^{2} \cdot \mathrm{hr} \cdot{ }^{\circ} \mathrm{F}$

Mylar. Strung window: $U \approx 0.28 \mathrm{Btu} / \mathrm{ft}^{2} \cdot \mathrm{hr} \cdot{ }^{\circ} \mathrm{F}$.

The mylar-strung window tested employed highly reflective (aluminized) 1 mil strips of mylar as convection defeating elements. The convection defeators employed in this (initial) test were not movable. 